\title{
Metabolic Capability of Penicillium oxalicum to Transform High Concentrations of Anti-Inflammatory and Analgesic Drugs
}

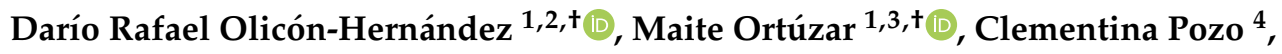 \\ Jesús González-López ${ }^{4}$ and Elisabet Aranda ${ }^{4, *(D)}$ \\ 1 Institute of Water Research, University of Granada. Ramón y Cajal, 4. Bldg Fray Luis., 18071 Granada, Spain; \\ magnadroh@hotmail.com (D.R.O.-H.); maiteortuzar@usal.es (M.O.) \\ 2 Instituto Politécnico Nacional, Escuela Nacional de Ciencias Biológicas, Carpio y Plan de Ayala s/n. Colonia \\ Santo Tomas, 11340 Ciudad de México, Mexico \\ 3 Department of Microbiology and Genetics Biology, Faculty of Biology, University of Salamanca, \\ 37007 Salamanca, Spain \\ 4 Institute of Water Research, Department of Microbiology, University of Granada. Ramón y Cajal, \\ 4. Bldg Fray Luis, 18071 Granada, Spain; clpozo@ugr.es (C.P.); jgl@ugr.es (J.G.-L.) \\ * Correspondence: earanda@ugr.es; Tel.: +34-958241000 (ext. 20379) \\ + Both authors contributed equally to this work.
}

Received: 19 February 2020; Accepted: 1 April 2020; Published: 4 April 2020

\begin{abstract}
Non-steroidal anti-inflammatory drugs (NSAIDs) and analgesics are two of the most employed drug groups around the world due to their use in the treatment of edema and pain. However, they also present an ecological challenge because they are considered as potential water pollutants. In this work, the biodegradation of four NSAIDs (diclofenac, ibuprofen, naproxen and ketoprofen) and one analgesic (acetaminophen) at $50 \mu \mathrm{M}$ (initial concentration) by Penicillium oxalicum, at both flask and bioreactor bench scales, was evaluated. An important co-metabolic mechanism as part of the global bioremediation process for the elimination of these drugs was observed, as in some cases it was necessary to supplement glucose to achieve a $100 \%$ removal rate: both individually and as a complex mixture. Identical behavior in the implementation of a fluidized bench-scale batch bioreactor, inoculated with pellets of this fungus and the complex mix of the drugs, was observed. The role of the cytochrome P450 enzymes (CYP) in the biodegradation of the drugs mix were evidenced by the observation of hydroxylated by-products. The results on the reduction of toxicity (micro and phyto) were not conclusive; however, a reduction in phytotoxicity was detected.
\end{abstract}

Keywords: ascomycetes; analgesics; emerging contaminants; biodegradation; non-steroidal anti-inflammatory drugs; Penicillium oxalicum

\section{Introduction}

Fungi are eukaryotic global organisms of paramount importance, able to colonize and survive in multiple marine and soil environments. As a consequence of the evolutionary process within this group, multiple roles in nature and different levels of organization have developed, including varied enzymatic and physiological activities [1]. Fungi combine intra- and extracellular processes to use a heterogeneous complex organic material as a carbon source to grow and survive, incorporating these materials into their metabolic pathways in the process. The morphological and enzymatic capabilities of these organisms allow them to degrade and/or remove large numbers and types of compounds (including xenobiotic substances) using both enzymatic and biophysical processes such as bioaccumulation and biosorption. For this reason, they are promising models to implement new eco-friendly technologies [2,3]. 
Non-steroidal anti-inflammatory drugs (NSAIDs) are compounds used to inhibit the production of prostaglandins to control pain and inflammation [4]. The constant use of NSAIDs has attracted the attention of the organizations that control the maximum levels of these substances in the environment. This has generated concern about the long-term side effects they may have and their impact on the environment. For example, in the USA, 29 million adults took NSAIDs at least three times per week for more than three months in 2010, and it is estimated that this amount increases year by year. This increase could also be as a consequence of evidence that links their use with the reduction of cancer metastasis and heart diseases [4,5]. Some NSAIDs, such as diclofenac, are part of a watchlist of substances under the Water Framework Directive 2013/39/EU, a surveillance action for the use of these drugs, normalizing their discharge into wastewater and emphasizing their study to determine their long-term side effects [6,7]. Analgesics are used for the treatment of pain. Paracetamol (acetaminophen) was the first drug to be made available over the counter and is one of the most used drugs in Europe, America and Oceania [8]. Because of the increased use, the concentrations of these drugs in urban wastewaters and their recirculation to the main water bodies are affected, which may represent an important environmental and health issue [3]. In some countries, the concentration of NSAIDs such as naproxen, ibuprofen and diclofenac in wastewater influent are $109 \mu \mathrm{g} / \mathrm{L} ; 603 \mu \mathrm{g} / \mathrm{L}$ and $115 \mu \mathrm{g} / \mathrm{L}$, respectively, and are not able to be completely eliminated in treatment processes. Also, concentration of naproxen $(6.8 \mu \mathrm{g} / \mathrm{L})$ and ibuprofen $(19.2 \mu \mathrm{g} / \mathrm{L})$ were detected in river water [9].

The potential of fungi as bioremediation tools for the elimination of drugs in wastewater using both ascomycetes and basidiomycetes models was reported. The reduction of the toxicity of effluent contaminated with pharmaceutical compounds treated with fungi systems is based on the biotransformation of the molecules, mainly by the extraordinary capability of some of the models to produce high amounts of extracellular lignin-modifying enzymes (LME) [3,10-12]. In addition, these works have tried to design efficient elimination systems at bench, pilot or industrial scales, usually by studying the biodegradation of drugs individually, or by using mixtures made according to quantification methods, or to avoid interferences in sterile and non-sterile conditions [13-17]. However, it has been shown that some of these fungi are inefficient at competing with autochthonous microorganisms in real conditions [18].

Previously, we reported the use of an unusual bioremediating ascomycete Penicillium oxalicum for the elimination of diclofenac. This fungus was isolated from a pond contaminated with polycyclic aromatic compounds (PAHs) and degraded extreme levels $(100 \mu \mathrm{M})$ of the compound in approximately $24 \mathrm{~h}$ mainly using cytochrome P450 (CYP450) flasks and bioreactors at bench-scale, resulting in a reduction of acute toxicity of the effluent [19]. Here, we explored the degradation of four NSAIDs and one analgesic, both individually and as a complex mix, by this fungus. The co-metabolic behavior was studied in the process. In addition, we performed (i) scaling of the process using free biomass in a fluidized bench bioreactor, (ii) evaluated the influence of glucose into the system for degradation of a complex mix of drugs, (iii) analyzed the metabolites of degradation and (iv) expanded toxicity studies including micro and phytotoxicity assays.

\section{Materials and Methods}

\subsection{Pharmaceutical Compound Stock Solutions and Microorganisms}

Diclofenac sodium salt (DFC; $\geq 98 \%$, Sigma Aldrich St. Louis, MO, USA); ketoprofen (KET; 98\% Alfa Aesar Tewksbury, MA, USA), ibuprofen (IBU; 99\% Alfa Aesar Tewksbury, MA, USA) and naproxen (NPX; 99\% Alfa Aesar Tewksbury, MA, USA) was selected as NSAIDs and acetaminophen (APAP; >98\% Sigma Aldrich St. Louis, MO, USA) as analgesic drugs. They were dissolved individually in distilled water (DFC and APAP) or acetonitrile (KET, IBU and NPX) at $5 \mathrm{mM}$ and $50 \mathrm{mM}$ as final concentrations. These stock solutions were used for the inoculation of flasks and the bioreactor in the evaluation of the degradation by P. oxalicum. Acetonitrile and water (high-performance liquid chromatography (HPLC) degree) were provided by VWR, Spain. 
The experiments were performed using the strain of Penicillium oxalicum ascension number MN412707.

2.2. Biodegradation of Individual Non-Steroidal Anti-Inflammatory Drugs (NSAIDs)/Analgesic by Penicillium oxalicum at Flask Scale

The amount of $1 \times 10^{5}$ spores $/ \mathrm{mL}$ of P. oxalicum were inoculated under sterile condition in sacrificial flasks containing $25 \mathrm{~mL}$ of modified Kirk medium ( $5 \mathrm{~g} / \mathrm{L}$ glucose; $2 \mathrm{~g} / \mathrm{L}$ ammonium tartrate; $1 \mathrm{~g} / \mathrm{L}$ monopotassium phosphate; $0.5 \mathrm{~g} / \mathrm{L}$ magnesium sulphate; $0.5 \mathrm{~g} / \mathrm{L}$ potassium chloride; $1 \mathrm{~g} / \mathrm{L}$ yeast extract; $5 \mathrm{~g} / \mathrm{L}$ peptone and $1 \mathrm{~mL} / \mathrm{L}$ oligoelements solution). The spores were collected according to our previously reported protocol [19]. Flasks were cultured at $28{ }^{\circ} \mathrm{C}$ with shaking at $120 \mathrm{rpm}$ for 2 days to form biomass pellets without any controlled light cycle. Afterwards, $100 \mu \mathrm{M}$ of each compound was added individually to the flasks and cultured under the same conditions. The effective concentration was $120 \mu \mathrm{M}$ for all the compounds, expect for diclofenac. These concentrations, considered as high concentrations for emerging contaminants (ECs), were selected due to the previously reported results where P. oxalicum is able to degrade this amount of diclofenac [19]. A heat-killed biomass control (biotic control) was used to evaluate the biosorption effect. Sacrificial flasks and biotic control flasks were taken every $24 \mathrm{~h}$ for a total of $120 \mathrm{~h}$ to evaluate the residual concentration of the pharmaceutical compounds, residual glucose concentration, $\mathrm{pH}$, and biomass (as described above). The experiments were carried out in triplicate.

\subsection{Biodegradation of a Complex Mixture of NSAIDs/Analgesic by P. Oxalicum at Flask Scale}

Unlike the individual degradation, the sacrificial flask was not used for the complex mixture. Sixty milliliters of the modified Kirk medium were added to flasks of $250 \mathrm{~mL}$ and the same concentration of spores were inoculated and cultivated under the same conditions for $48 \mathrm{~h} \mathrm{[19].} \mathrm{A} \mathrm{complex} \mathrm{mix} \mathrm{of}$ $250 \mu \mathrm{M}$ of NSAIDs/analgesic (50 $\mu \mathrm{M}$ of each) was supplemented after this time. These concentrations were selected to ensure the degradation system did not saturate. Two systems were designed for this stage: (a) active biomass without glucose supplementation (control system); and (b) active biomass with $3 \mathrm{~g} / \mathrm{L}$ of glucose supplementation every $48 \mathrm{~h}$ (feed system). The biotic control (heat-killed biomass control) was also tested under these conditions. Samples were taken from the 3 systems under sterile conditions through a side tube coupled to the bioreactor for 7 days every $24 \mathrm{~h}$ to measure drug concentration, biomass, residual glucose and $\mathrm{pH}$. The experiments were performed in triplicate.

\subsection{Biodegradation of Complex Mixture of NSAIDs/Analgesic by Penicillium oxalicum in Fluidized Bioreactor}

A 3 L Schott bench reactor (Duran Group, Mitterteich, Germany) equipped with electrodes for $\mathrm{pH}$, temperature and dissolved oxygen control (Broadley-James ${ }^{\circledR}$, Irvine, CA, USA) was used. Free biomass pellets were produced separately in a $500 \mathrm{~mL}$ flask for $48 \mathrm{~h}$ under the conditions described previously. The bioreactor was inoculated with this biomass, an identical amount of drug as used in the flask-scale and fresh optimized culture media (diluted to $30 \%$ volume based [19]). Samples of $15 \mathrm{~mL}$ were taken every $3 \mathrm{~h}$ over a $12 \mathrm{~h}$ period and then every $12 \mathrm{~h}$ for 8 days. The drug concentrations, residual glucose concentration, $\mathrm{pH}$, temperature, and dissolved oxygen were measured from each sample harvested. The bioreactor was supplemented with $2.5 \mathrm{~g} / \mathrm{L}$ of glucose under sterile conditions every $48 \mathrm{~h}$ to increase the biodegradation.

\subsection{Analytical Methods}

The biomass and $\mathrm{pH}$ were evaluated by classic methods (gravimetric and $\mathrm{pH}$ test strips). Residual glucose was determined by Miller's method (dinitrosalicylic acid) [20].

For the quantification of individual NSAIDs/analgesic, a high-performance liquid chromatography system (HPLC) Agilent 1050 (MAEU, USA) and HPLC Waters Alliance 2690 (Waters, Milford, USA) were used. The HPLC elution was carried out with a Synergi Fusion RP C-18 column ( $80 \AA ; 4 \mu \mathrm{m}$, 
$4.6 \times 150 \mathrm{~mm}$; Phenomenex ${ }^{\circledR}$, Madrid, Spain) coupled to a diode array detector. The separation was performed using water $+1 \%$ phosphoric acid-acetonitrile in a ratio of 15:85 for DFC, IBU, KET and NPX and 75:25 for APAP determination, both in isocratic flow.

The complex mixture degradation was quantified using an ultra-high performance liquid chromatography (UHPLC) Acquity I-Class System (Waters, Milford, USA) and a Synapt G2S QToF mass spectrometer (Waters, Milford, USA) coupled to a CORTECS-UHPLC ${ }^{\circledR}$ HILIC ${ }^{\circledR}$ C18 $1.6 \mu \mathrm{m}$ column $(2.1 \times 50 \mathrm{~mm}$; Waters, Milford, USA) connected to a photodiode Array detector. Ten microliters of the sample were injected and a gradient flow $(0.350 \mathrm{~mL} / \mathrm{min})$ composed of water- $0.1 \% \mathrm{NH} 3(\mathrm{~A})$ and acetonitrile- $0.1 \% \mathrm{NH} 3$ (B) (5 min A 80\%-B 20\%; 10 s A 30\%-B 70\%; $1.40 \mathrm{~min}$ A $0 \%-\mathrm{B} 100 \%$ and 1.10 min A 80\%-B 20\%) was used. The same procedure was employed for flask and bioreactor bench-scale reactions. Using the same equipment and conditions the metabolites analysis was created according to our previously reported protocol using the MassLynx software (version 4.1, Waters, Milford, USA) [21].

\subsection{Analysis of NSAIDs/Analgesic Effluent Toxicity in the Fluidized Bioreactor}

The Microtox ${ }^{\circledR}$ bioassay test was used to measure the acute toxicity of the samples following fungal conversion, based upon changes in the luminescence of Allivibrio fischeri. For this, a Microtox Model 500 toxicity analyzer (Instrumentación Analítica SA Madrid, Spain) was used according to our previous report [19]. The toxicity was expressed as EC50 (\%) defined as the concentration which provokes a $50 \%$ light reduction on $A$. fischeri after 5 and $15 \mathrm{~min}$ of exposure. Samples were analyzed at 0, 30, 96, 108 and $192 \mathrm{~h}$.

The phytotoxicity test was performed according to the method of Zucconi et al. (1981) which consists in measuring the germination index (GI) of garden cress seeds (Lepidium sativum L.). The tests were carried out in $9 \mathrm{~cm}$ diameter Petri dishes with a disc of Whatman paper No. 1, to which $2 \mathrm{~mL}$ of the bioreactor extract at the initial, and final time point of biodegradation, was added at different concentrations $(100 \%, 80 \%, 40 \%, 20 \%$ and $10 \%)$, with distilled water as a control. Finally, 20 cress seeds per dish were distributed on the Whatman paper, impregnated with the effluent or control and incubated at $28{ }^{\circ} \mathrm{C}$ in the dark for $48 \mathrm{~h}$. The number of germinated seeds per plate was counted and the root length was determined by a scale meter. Three repetitions were performed per treatment. The percentage of the GI was determined according to the following equation [22]:

$$
G I=\frac{G o-G}{L o-L} \times 100
$$

$G I$ = germination index;

Go = seeds germinated in control;

$G=$ seeds germinated in effluent;

$L o=$ Measurement of the root length in the control;

$L=$ Measurement of the root length in the effluent.

\subsection{Statistical Analysis}

The software sp14 (SYSTAT software, Inc. San Jose, CA, USA) was used for statistical analyses. The normality test was made by Shapiro-Wilk analysis with significance $p$ value of 0.05 . In the case of individual biodegradation, one-way analysis of variance (ANOVA) was carried out taking the residual concentration as the response. In the case of complex mixture biodegradation at flask scale, two-way ANOVA was performed taking the supplementation glucose and time as variables. In both, the significance difference was determined by Tukey test $(p<0.05)$. Only systems inoculated with active biomass were evaluated. Since the bioreactor was considered as a complex individual system, no statistical analysis was made at this scale. In the case of the toxicity test, the statistic validation was made by one-way ANOVA. 


\section{Results}

\subsection{Degradation of Individual Pharmaceutical Compounds by the Ascomycete P. oxalicum at Flask-Scale}

Figure 1 represents the results of the individual elimination of each drug tested in this work expressed as global removal rate considering the final time and final residual concentration (the data have a normal distribution according to the normality test, $p>0.05)$. Under the selected experimental conditions P. oxalicum completely degraded APAP and IBU (4.17 $\mu \mathrm{M} / \mathrm{h}$ both, 100\%), as well as DFC $(2.08 \mu \mathrm{M} / \mathrm{h}, 100 \%)$ at $24-48 \mathrm{~h}$, corroborating our previous DFC report [19]. In addition, partial degradation of NPX $(0.58 \mu \mathrm{M} / \mathrm{h}, 70 \%)$ and KET was observed, with the latter compound being the most recalcitrant of the evaluated compounds (approximately $<15 \%$ of the removal rate in $120 \mathrm{~h}$ ). The statistical analysis corroborated the results. The biomass, $\mathrm{pH}$ and glucose concentration did not show significant changes.

\section{a}

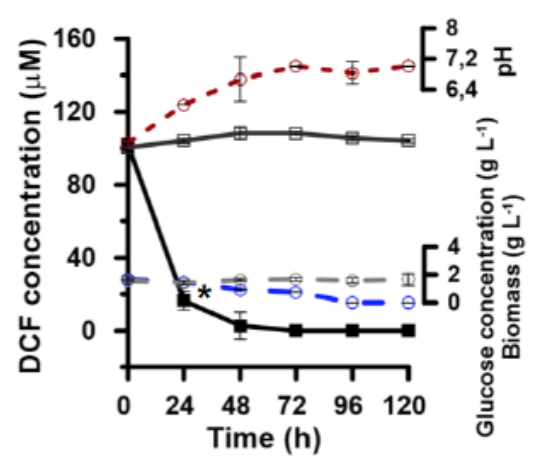

b
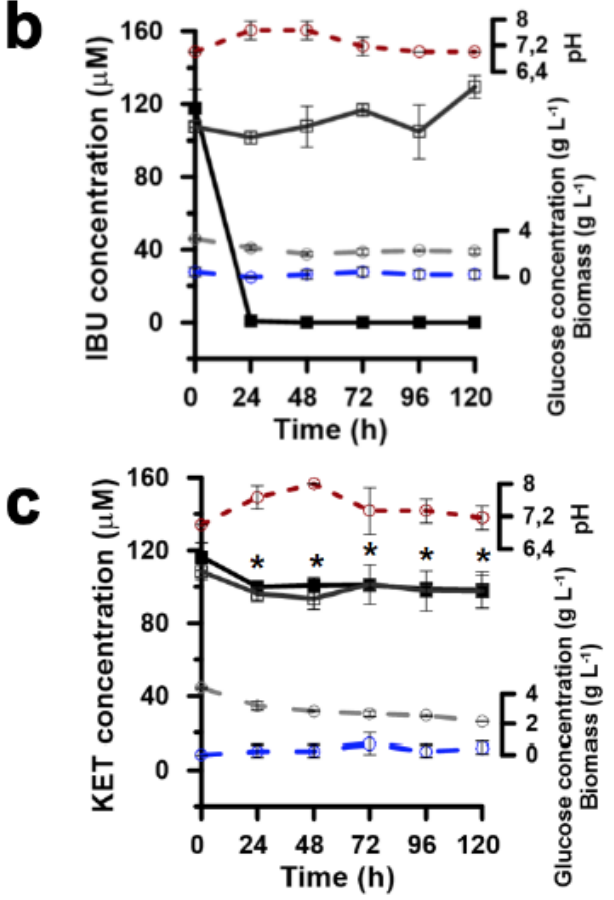

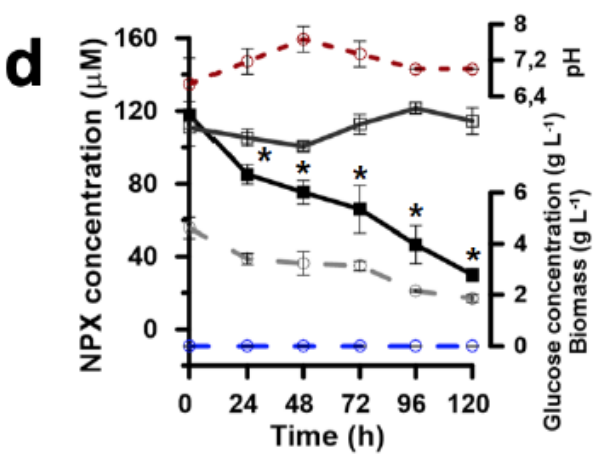

e

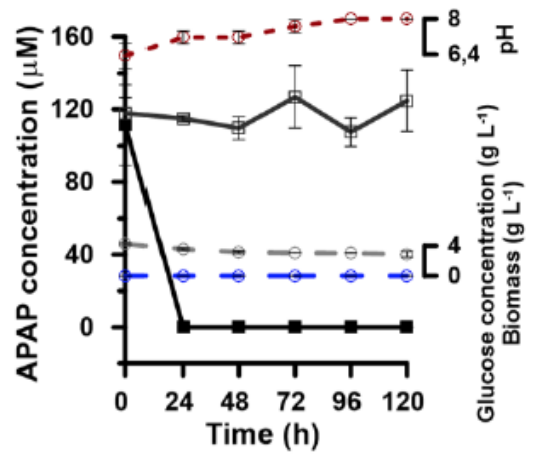

Figure 1. Individual degradation at flask-scale: $\mathrm{pH}$ and glucose concentration of the tested pharmaceutical compounds by Penicillium oxalicum in relation to biodegradation of the drugs. (a) Diclofenac (DFC); (b) ibuprofen (IBU); (c) ketoprofen (KET); (d) naproxen (NPX); and (e) acetaminophen (APAP). Biotic control corresponds to a heat-killed biomass control. The values are presented as the average of three independent experiments \pm standard deviation $(n=3)$. Asterisks $\left(^{*}\right)$ indicates statistical significance differences using Tukey's test $(p<0.05)$. 
3.2. Analysis of Biodegradation Rates from a Complex Mix of NSAIDs/Analgesic Drugs by Penicillium oxalicum under Increasing Glucose Concentration

NSAIDs and analgesic removal from a complex mix is shown in Figure 2. According to the previous results, we hypothesized that degradation of a complex mixture would require supplementation of glucose to reach $100 \%$ of elimination. In this context, the biodegradation of APAP and IBU as part of this mixture were not affected by the addition of glucose into the media and were similar to the results in Section 3.1 (Figure 1). However, a significant decrease of DFC removal rate was observed in the system without glucose supplementation compared to the results observed in individual biotransformation, with total elimination of this compound in the complex mix not achieved, even by $168 \mathrm{~h}$. NPX and KET removal rates had similar results.
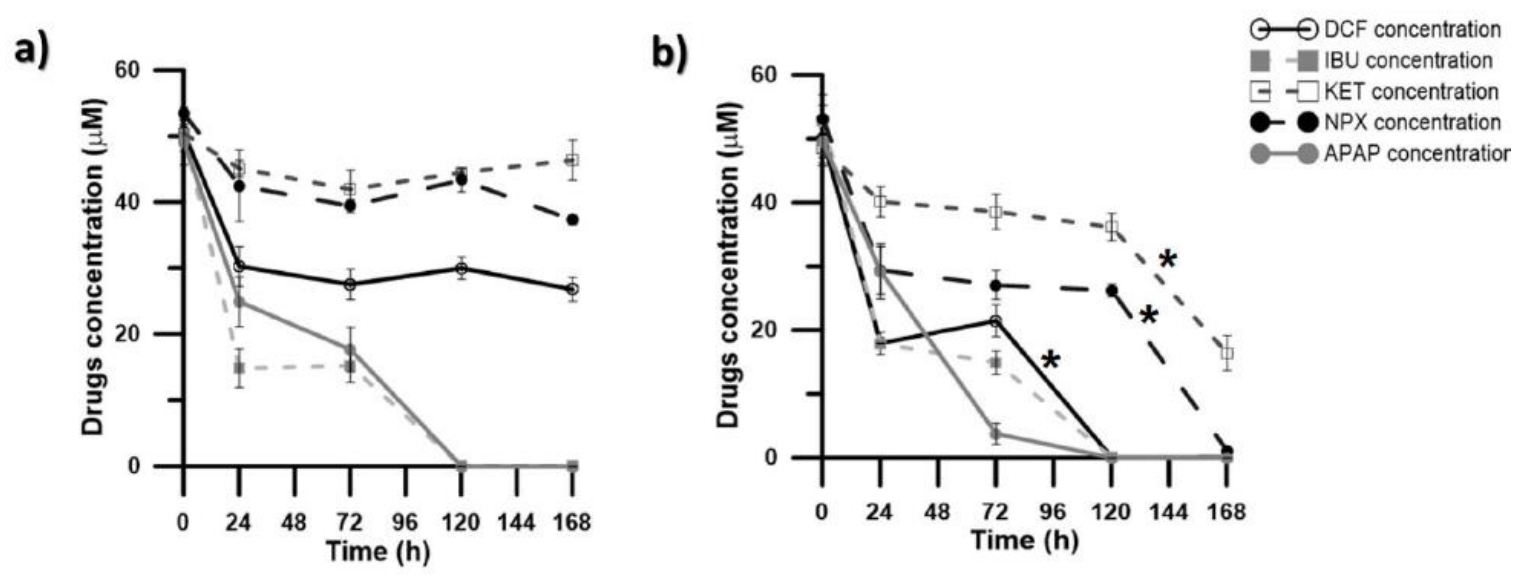

Figure 2. Biodegradation of a complex mix of non-steroidal anti-inflammatory drugs (NSAIDs)/analgesic by Penicillium oxalicum at flask-scale. (a) Control system $=$ Active biomass without glucose supplementation $(\mathbf{b})$ Feed system $=$ Active biomass with $3 \mathrm{~g} / \mathrm{L}$ of glucose supplementation every $48 \mathrm{~h}$. The biotic control did not show a significant difference and was similar to individual biodegradation (data not shown). Key: acetaminophen (APAP); diclofenac (DFC); ibuprofen (IBU); ketoprofen (KET); and naproxen (NPX). The values are presented as the average of three independent experiments \pm standard deviation $(n=3)$. Asterisks $\left.{ }^{*}\right)$ indicates statistical significance differences using Tukey test $(p<0.05)$.

In contrast, an improvement in the removal rate of DFC, NPX and KET was observed in the feed system, suggesting that glucose concentration has a key role in the biodegradation of mixtures of pharmaceutical compounds by this fungus. The changes in $\mathrm{pH}$ and glucose depletion can be observed in the supplementary material (Figure S1).

The statistical analysis (Table 1) demonstrated that the supplementation of $3 \mathrm{~g} / \mathrm{L}$ of glucose positively influences the biodegradation of DFC, KET and NPX and not affected the degradation of IBU and APAP, as previously mentioned. The comparison was made to determine the effect of the addition of glucose in each pharmaceutical compound, no comparison was made between them.

\subsection{Pellets of P. oxalicum Degrade a Complex Mix of NSAIDs/Analgesic in a Batch Fluidized Bioreactor with Glucose Supplementation}

The results of scaling-up the transformation of NSAIDs/analgesic at bioreactor bench scale by the selected model fungus are shown in Figure 3. At bioreactor scale, almost all of the pharmaceutical compounds were eliminated at $192 \mathrm{~h}$, with traces of KET at this time. Deviations in the concentration of the compounds in the initial stage of the experiment can be caused by phenomena of biosorption and desorption due to the stabilization of the system. According to the results shown in Section 3.2, glucose addition was necessary for the treatment of the medium added with a mixture of drugs: the reason why only the feed system was scaled-up. Increases of glucose consumption were observed 
throughout the entire process. Temperature and dissolved oxygen did not have significant changes. At this point it is important to note that the fact that the concentration of dissolved oxygen in the medium was low indicates that the oxygen is being used by the fungus in an aerobic process, which prevents accumulation of oxygen in the culture medium.

Table 1. Statistical analysis of the influence of glucose supplementation in the biodegradation of NSAIDs/analgesic complex mixture by P. oxalicum.

\begin{tabular}{|c|c|c|c|c|c|c|c|c|c|c|}
\hline \multirow{2}{*}{ Time (h) } & \multicolumn{2}{|c|}{ DFC } & \multicolumn{2}{|c|}{ IBU } & \multicolumn{2}{|c|}{ KET } & \multicolumn{2}{|c|}{ NPX } & \multicolumn{2}{|c|}{ APAP } \\
\hline & $\mathrm{g}+$ & g- & g+ & g- & $\mathrm{g}+$ & g- & g+ & g- & $g+$ & g- \\
\hline 0 & a & $\mathrm{a}$ & a & a & a & a & a & $\mathrm{a}$ & $\mathrm{a}$ & $\mathrm{a}$ \\
\hline 24 & a & $\mathrm{b}$ & a & a & $\mathrm{a}$ & $\mathrm{b}$ & a & $\mathrm{b}$ & $\mathrm{a}$ & $\mathrm{a}$ \\
\hline 48 & $\mathrm{a}$ & $b$ & a & a & a & a & a & $\mathrm{b}$ & $\mathrm{a}$ & $\mathrm{a}$ \\
\hline 72 & a & $\mathrm{b}$ & $\mathrm{a}$ & a & $\mathrm{a}$ & $\mathrm{b}$ & a & $\mathrm{b}$ & $\mathrm{a}$ & $\mathrm{a}$ \\
\hline 96 & a & $b$ & $\mathrm{a}$ & a & $\mathrm{a}$ & $\mathrm{b}$ & a & $\mathrm{b}$ & $\mathrm{a}$ & $\mathrm{a}$ \\
\hline 120 & a & $\mathrm{b}$ & a & a & $\mathrm{a}$ & $\mathrm{b}$ & a & $\mathrm{b}$ & $\mathrm{a}$ & $\mathrm{a}$ \\
\hline Global Behavior & \multicolumn{2}{|c|}{ Affected } & \multicolumn{2}{|c|}{ Not affected } & \multicolumn{2}{|c|}{$\begin{array}{c}\text { Affected at final time of } \\
\text { biodegradation }\end{array}$} & \multicolumn{2}{|c|}{ Affected } & \multicolumn{2}{|c|}{ Not affected } \\
\hline
\end{tabular}

$\mathrm{g}+=3 \mathrm{~g} / \mathrm{L}$ glucose supplementation; $\mathrm{g}-=$ Without glucose supplementation. APAP $=$ acetaminophen; DFC $=$ diclofenac; IBU = ibuprofen; KET = ketoprofen; NPX = naproxen. Different letters indicate statistical significance difference using Tukey test $(p<0.05)$.

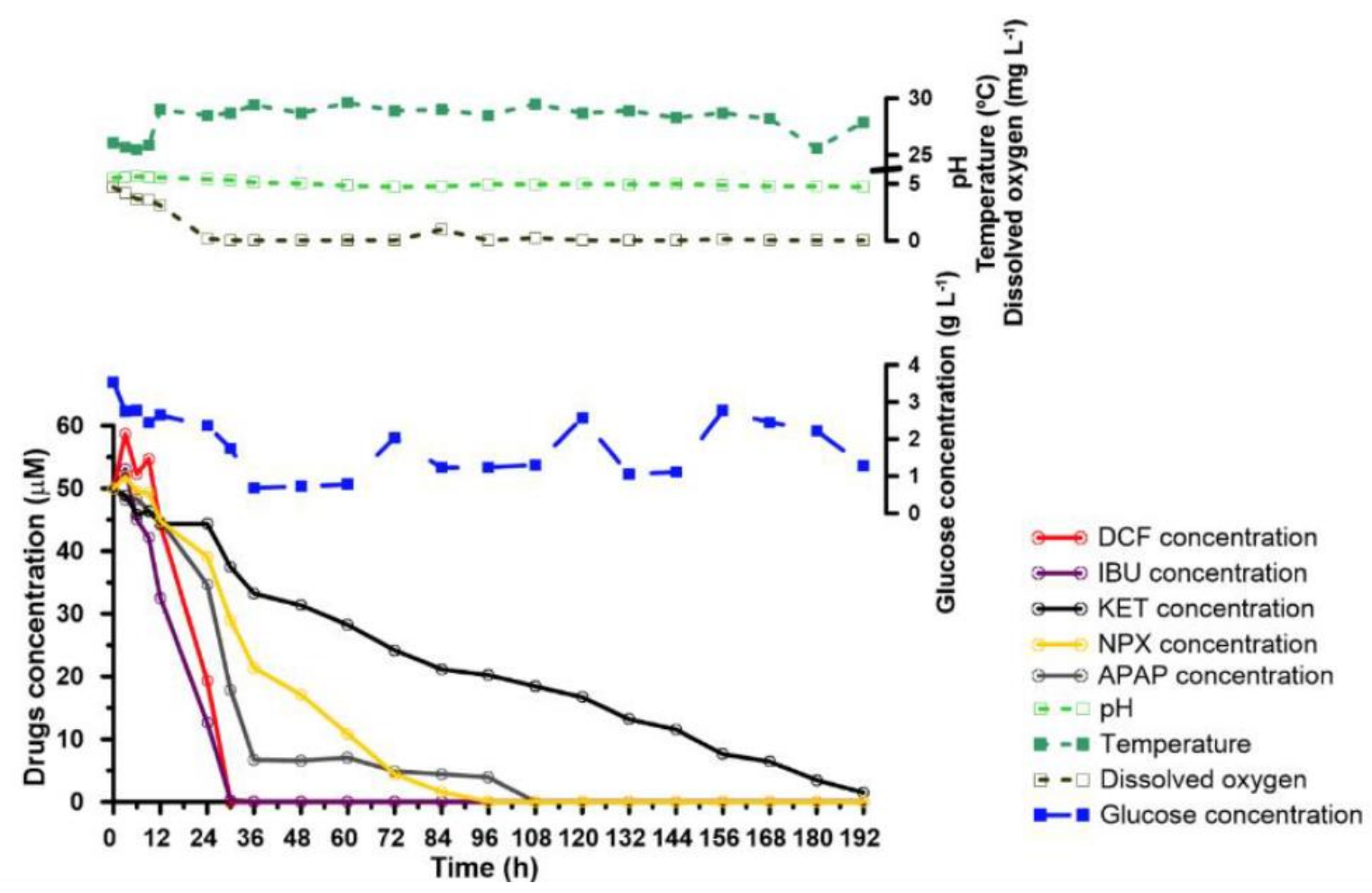

Figure 3. Biodegradation evolution of the NSAIDs/analgesic mix at batch feed bioreactor scale by Penicillium oxalicum. A liquid growth degradation system incubated for $192 \mathrm{~h}$ was used under agitation and aeration. Key: acetaminophen (APAP); diclofenac (DFC); ibuprofen (IBU); ketoprofen (KET); and naproxen (NPX).

3.4. By-Products Obtained during the Biotransformation of the NSAIDs/Analgesic Mixture by Penicillium oxalicum

Characteristics of the different by-products found in the degradation of the tested pharmaceutical compounds are represented in Table 2. The hydroxylated metabolites predominated in the 
degradation of the complex mixture, seeing as they were present in the degradation of all the tested pharmaceutical compounds.

Table 2. By-products obtained in the biodegradation of NSAIDs/analgesic mix.

\begin{tabular}{|c|c|c|c|c|}
\hline Metabolite & Molecular Formula & Retention Time (min) & $m / z$ & Error (ppm) \\
\hline 3-hydroxy-acetaminophen & $\begin{array}{l}\text { ACETAMINOPHEN } \\
\mathrm{C}_{8} \mathrm{H}_{9} \mathrm{NO}_{3} \\
\text { DICLOFENAC }\end{array}$ & 0.66 & 168.0686 & 14.9 \\
\hline $\begin{array}{l}\text { 4-hydroxy-diclofenac } \\
\text { 5-hydroxy-diclofenac }\end{array}$ & $\mathrm{C}_{14} \mathrm{H}_{11} \mathrm{Cl}_{2} \mathrm{NO}_{3}$ & 4.70 & 312.0213 & 6.1 \\
\hline 4, 5-dihydroxy-diclofenac & $\begin{array}{c}\mathrm{C}_{14} \mathrm{H}_{11} \mathrm{Cl}_{2} \mathrm{NO}_{4} \\
\text { IBUPROFEN }\end{array}$ & 6.85 & 328.0143 & 5.5 \\
\hline 1-oxo-ibuprofen & $\begin{array}{c}\mathrm{C}_{13} \mathrm{H}_{16} \mathrm{O}_{3} \\
\text { KETOPROFEN }\end{array}$ & 5.80 & 221.1178 & -13.6 \\
\hline $\begin{array}{l}\text { 2-[3-(3-hydroxybenzoyl) phenyl]-propanoic acid } \\
\text { 2-[3-(4-hydroxybenzoyl) phenyl]-propanoic acid } \\
\text { 2-(3-benzoyl-4-hydroxyphenyl)-propanoic acid }\end{array}$ & $\mathrm{C}_{16} \mathrm{H}_{14} \mathrm{O}_{4}$ & 1.38 & 271.0970 & -11.8 \\
\hline 2-[3-(3,4-dihydroxybenzoyl) phenyl]-propaoic acid & $\mathrm{C}_{16} \mathrm{H}_{14} \mathrm{O}_{5}$ & 1.48 & 287.0919 & -9.8 \\
\hline $\begin{array}{c}2-[(3-\text { hydroxy(phenyl)methyl) phenyl]-propanoic } \\
\text { acid }\end{array}$ & $\mathrm{C}_{16} \mathrm{H}_{16} \mathrm{O}_{3}$ & 2.48 & 257.1178 & -3.1 \\
\hline $\begin{array}{l}\text { 1-(6-methoxynaphthalen-2-yl) ethanone } \\
\text { 2-(6-hydroxynaphthalen-2-yl) propanoic acid }\end{array}$ & $\begin{array}{l}\text { NAPROXEN } \\
\mathrm{C}_{13} \mathrm{H}_{12} \mathrm{O}_{2} \\
\mathrm{C}_{13} \mathrm{H}_{12} \mathrm{O}_{3}\end{array}$ & $\begin{array}{l}0.84 \\
0.55\end{array}$ & $\begin{array}{l}201.0916 \\
217.0865\end{array}$ & $\begin{array}{l}-10.9 \\
-16.1\end{array}$ \\
\hline
\end{tabular}

In Figure 4, the partial degradation pathway of each drug is represented. In this case, the elimination of the metabolites of the NSAIDs biodegradation is not possible since existed metabolite accumulation, especially KET by-products.

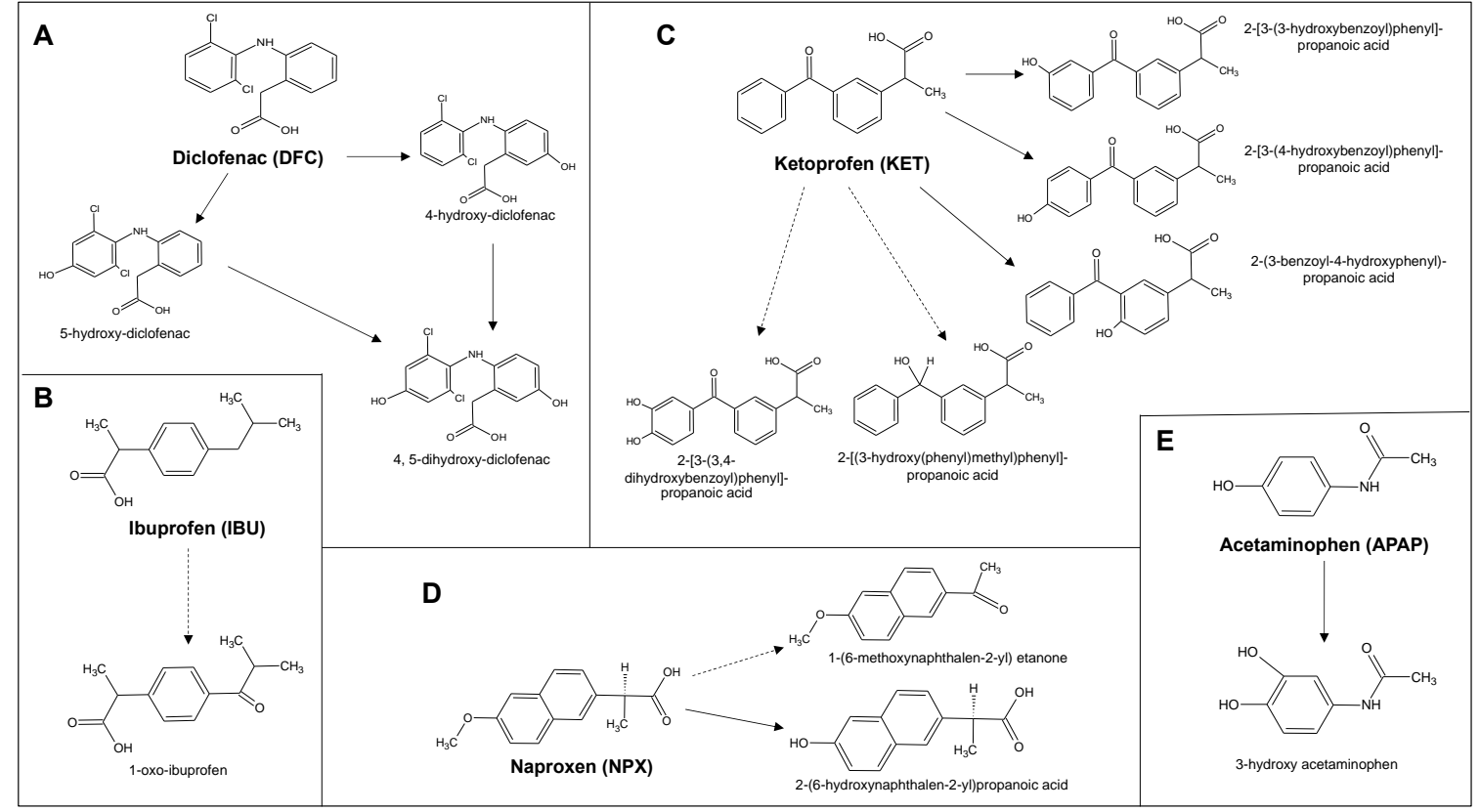

Figure 4. Representation of the partial biodegradation pathways of the tested drugs based on the different metabolites detected by ultra-high performance liquid chromatography (UHPLC) quadrupole time-of-flight (QToF) mass spectrometer. (A) diclofenac (DFC); (B) ibuprofen (IBU); (C) ketoprofen (KET); (D) naproxen (NPX) and (E) acetaminophen (APAP). The continuous arrow indicates direct transformation and the dashed arrow secondary transformation.

\subsection{Analysis of Micro- and Phyto-Toxicity of Bioreactor Effluent Treated with Penicillium oxalicum}

It was observed that the treatment with P. oxalicum did not reduce toxicity throughout the test. This was due to high toxicity (EC50 $5 \mathrm{~min}=7.5 \pm 0.6 \%$ and EC50 $15 \mathrm{~min}=7.8 \pm 0.5 \%$ ) remaining within the samples without significant changes (Figure 5a). The control and the sample at $192 \mathrm{~h}$ have 
statistically significant difference with the rest of the samples and no significant differences were observed between 5 and 15 min of exposure. In contrast, a reduction of phytotoxicity (displayed by an increase in GI) was observed in the effluent treatment with this fungus (up to $92 \pm 13$ depending on dilution) compared with the control (Figure $5 b$ ).
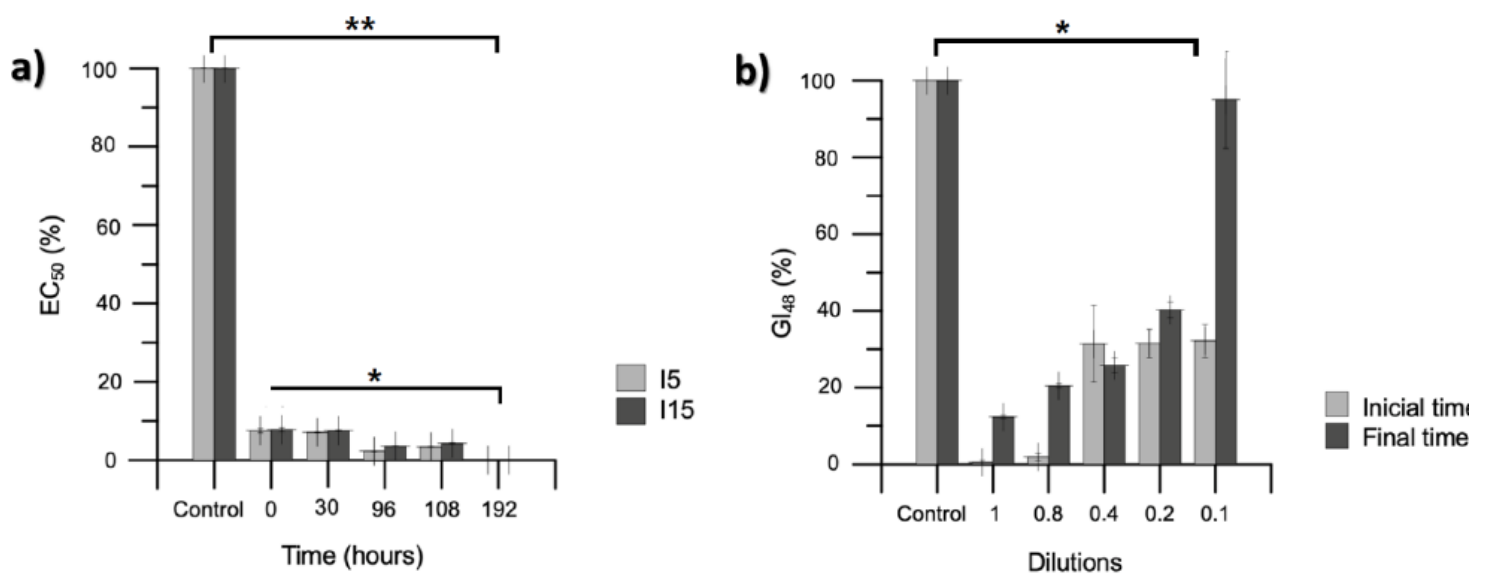

Figure 5. Analysis of the toxicity of effluent inoculated with NSAIDs/analgesic treated with Penicillium oxalicum in a batch feed fluidised bioreactor at different incubation times. (a) Microtoxicity of samples taken at 0, 30, 96, $108192 \mathrm{~h}$; the control corresponds to the measurement of the microtoxicity of the medium without drugs and the fungus. (b) Phytotoxicity by calculation of the germination index (GI) at $48 \mathrm{~h}$, the initial time point corresponds to the initial conditions of drug concentration in the bioreactor $(250 \mu \mathrm{M})$. The final time point corresponds to a value of $>99 \%$ drug degradation after $192 \mathrm{~h}$ of treatment. The control corresponds to the measurement of the GI using distilled water. The values are presented as the average of three independent experiments \pm standard deviation $(n=3) .{ }^{* *}=p<0.01 ;^{*}=p<0.05$.

\section{Discussion}

Here we demonstrated the versatility of an uncommon model (P. oxalicum), used in the biotransformation of four anti-inflammatory and one analgesic compound. Previously demonstrated was the capability of this fungus to degrade polycyclic aromatic compounds and diclofenac [19,23], however, the degradation of a complex mix of drugs was unexplored in this model.

There are reports of degradation in mixtures of pharmaceutical compounds with fungi. In this context, the ability of the white-rot fungi Trametes versicolor was tested in the biodegradation of a mix of diclofenac, ibuprofen, naproxen and ketoprofen, with $0.03 \mu \mathrm{M}$ as the initial concentration of each drug. It was observed that under experimental conditions a complete removal rate of 4 of these drugs was achieved in $48 \mathrm{~h}$, with the exception of ketoprofen [24]. The degradation time results are consistent with those obtained in the present work. This is despite the greater level of efficiency of P. oxalicum, when starting from concentrations of $50 \mu \mathrm{M}$ of each drug. The degradation efficiency of the ascomycete model P. oxalicum was compared with the basidiomycetes Bjerkandera sp. R1, Bjerkandera adusta and Phanerochaete chrysosporium. In this case, degradation of several pharmaceutical compounds and personal care products was observed in these models. This included anti-inflammatory drugs (diclofenac, ibuprofen and naproxen), antidepressants (citalopram and fluoxetine), psychiatric drugs (diazepam), antibiotics (sulfamethoxazole), anti-epileptics (carbamazepine) and fragrances (celestolide, galaxolide and tonalide). The versatility of both systems was similar and a $100 \%$ removal rate was achieved in almost all cases [16].

It was demonstrated that fungi can degrade a variety of compounds for bioremediation purposes under different conditions. Achieving high removal rates is a challenge that occurs in the processes of bioremediation, and one that relies on the specific mechanism (intra- and/or extracellular) of each fungus. For example, the degradation observed by co-metabolic mechanisms of carbamazepine, sulfamethoxazole and sulfametizole by Aspergillus niger was a removal rate of $20 \%$ [25]. 
Authors suggested that the complex chemical structure might affect the removal rate. In contrast, with the use of Trametes versicolor it was possible to completely degrade naproxen (31.4 $\mu \mathrm{M}$ as initial concentration) in less than six hours by a mix of intra- and extracellular processes [14].

In this work, we reported that glucose concentration affects the ability of P. oxalicum to degrade a complex mix of pharmaceutical compounds. It was suggested that fungi have a co-metabolic tendency towards the elimination of xenobiotics [3]; for example, in the biodegradation of several antibiotics by A. niger, where the biodegradation depended on an accessible carbon source [25]. Additionally, in the biodegradation of pyrene by Pseudotrametes gibbosa in the presence of co-substrates, the biodegradation efficiency of this PAH ranged from $34.23 \%$ to $50.64 \%$ [26].

In general, fungi can use two systems to degrade pharmaceutical compounds; the first is the system related to lignin-modifying (LME) extracellular enzymes (mainly associated with basidiomycetes), and secondly, the detoxification system mediated by CYP450 enzymes. The latter were responsible for the elimination of xenobiotics in fungi lacking an extracellular ligninolytic system [3]. Some aspergilla can remove pharmaceutical compounds under saline conditions [27], and are mediated by LME (esterases, laccases and peroxidases). It has been shown that in most cases both systems act together, regardless of the type of fungus. We reported the importance of CYP enzymes in the biodegradation of DFC in this model [19]. In this work, the obtained results also suggest that this type of enzyme could be implicated in the formation of hydroxylated metabolites (found in the biodegradation of all drugs) as part of the global mechanism. This result, as well as the metabolites observed in the supernatant of the bioreactor inoculated with P. oxalicum in the biodegradation of the complex mix, was consistent with those previously reported $[10,13,14,28]$.

In the bioreactor scaling process, $P$. oxalicum showed higher efficiency in degradation than at flask scale, evidencing a possible and efficient scaling process. Few studies have focused on the degradation of pharmaceutical compounds at the bioreactor scale with ascomycetes fungi, however, the use of white-rot fungi has been extensively explored. For example, the basidiomycete T. versicolor has been studied for the elimination of carbamazepine in air-bed fluidized bioreactors, in both continuous and discontinuous mode. This ligninolytic fungus removes $200 \mu \mathrm{g} / \mathrm{L}$ in 3 days in continuous mode and 25 days in discontinuous mode [29]. The latter result evidences the high efficiency of the system reaching the total elimination in 8 days of treatment in the same discontinuous mode. Furthermore, another study of $\mathrm{T}$. versicolor in a bioreactor with hospital wastewater showed that diclofenac, ibuprofen, naproxen, paracetamol and phenazone in the form of a complex mixture (initial amount of drugs of $1475 \mu \mathrm{g} / \mathrm{L}$ ) were eliminated with an efficacy of $80 \%$ after $24 \mathrm{~h}[17,30]$.

It was reported that the main intracellular pathway for the metabolism of drugs in fungi is by the action of CYP450 enzymes. They are a large group of enzymes that are related to many cellular processes, where certain clans have been associated in the degradation of aromatics compounds by hydroxylation of the main ring [3]. In this work, the presence of various mono-, and di-hydroxylated compounds was evidenced (i.e., 3-hydroxy-acetaminophen; 4, 5-dihydroxy-diclofenac; 2-[3-(3,4-dihydroxybenzoyl) phenyl]-propanoic acid) as the result of the CYP450 enzymes action. The presence of these hydroxylated derivatives has already been discussed previously in works that involve the degradation of NSAIDs by the action of fungi. For example, Marco-Urrea et al. (2009; 2010a; 2010b) describe the same type of metabolites in the degradation of NPX, IBU and KET by the use of T. versicolor under different conditions $[10,13,14]$. It was demonstrated that $T$. versicolor possess a versatile system for the degradation of drugs using extracellular (Laccases) and intracellular (CYP450) enzymes [31]. In the case of P. oxalicum, only the CYP450 enzymes seem to participate in the degradation of NSAIDs [19].

Ketoprofen was the most recalcitrant drug and its metabolites accumulated in the medium during biodegradation. This could be the cause of the high toxicity of the medium evaluated, and is suggested by the increase in the EC50 values from the Microtox assay. However, the drug was not toxic to $L$. sativum at a dilution of 0.1 ; denoting that the vegetal tissues have a greater tolerance to the effluent composition. This suggests that it would be necessary to evaluate the process under more realistic concentrations of NSAIDs and analgesic and also go deeper into the acute toxicity. The process could be 
optimized by analyzing the contribution of the hydroxylated metabolites of the drugs, if they represent dead-end products, or, if these metabolites can be degraded by the fungus itself.

\section{Conclusions}

P. oxalicum represents an effective and versatile tool for the elimination of high concentrations of diclofenac, ibuprofen and acetaminophen, and to some extent, naproxen and ketoprofen at flask and bioreactor scales. This fungus degrades the mix of NSAIDs/analgesic by co-metabolic mechanisms, therefore, requiring the addition of complementary carbon sources for total elimination. As a result of the degradation of the pharmaceutical compounds, P. oxalicum produced (mainly) hydroxylated metabolites in all cases. The treatment of effluents supplemented with these drugs with P. oxalicum reduces the phytotoxicity of the effluent, but does not reduce the microtoxicity. This is likely due to the high concentration and persistence of ketoprofen and its metabolites. Although this fungus has a potential use for bioremediation purposes, it is important to improve the nutritional conditions in order to apply it in a water-treatment plant.

Supplementary Materials: The following are available online at http://www.mdpi.com/2076-3417/10/7/2479/s1: Figure S1: Changes in $\mathrm{pH}$ and glucose concentration in the biodegradation of a complex mix of NSAIDs/analgesic by Penicillium oxalicum at flask-scale.

Author Contributions: Conceptualization, D.R.O.-H., M.O. and E.A.; experimentation and methodology, M.O. and D.R.O.-H.; resources, E.A., C.P. and J.G.-L.; writing-original draft preparation, D.R.O.-H. and M.O.; writing-review and editing, E.A., C.P., J.G.-L. All authors have read and agreed to the published version of the manuscript.

Funding: MINECO-ERDF funds [RYC-2013-12481] and [CTM- 2017-84332, MINECO/AEI/ERDF, UE]. CONACyT (231581/454815).

Acknowledgments: Olicón-Hernández would like to thank Consejo Nacional de Ciencia y Tecnología (CONACyT) for the postdoc fellowships (231581/454815). E. A. would like to thank the Ministry of Economy and Competitiveness (MINECO) and European Regional Development Fund (ERDF) funds [RYC-2013-12481] and [CTM- 2017-84332, MINECO/AEI/FEDER, UE].

Conflicts of Interest: The authors declare no conflict of interest.

\section{References}

1. Anastasi, A.; Tigini, V.; Varese, G.C. The Bioremediation Potential of Different Ecophysiological Groups of Fungi. In Fungi as Bioremediators; Goltapeh, E.M., Danesh, Y.R., Varma, A., Eds.; Springer: Berlin/Heidelberg, Germany, 2013; pp. 29-49. [CrossRef]

2. Marco-Urrea, E.; García-Romera, I.; Aranda, E. Potential of non-ligninolytic fungi in bioremediation of chlorinated and polycyclic aromatic hydrocarbons. New Biotechnol. 2015, 32, 620-628. [CrossRef] [PubMed]

3. Olicón-Hernández, D.R.; González-López, J.; Aranda, E. Overview on the Biochemical Potential of Filamentous Fungi to Degrade Pharmaceutical Compounds. Front. Microbiol. 2017, 8. [CrossRef] [PubMed]

4. Zhou, Y.; Boudreau, D.M.; Freedman, A.N. Trends in the use of aspirin and nonsteroidal anti-inflammatory drugs in the general U.S. population. Pharmacoepidemiol. Drug 2014, 23, 43-50. [CrossRef] [PubMed]

5. Bowers, L.W.; Maximo, I.X.F.; Brenner, A.J.; Beeram, M.; Hursting, S.D.; Price, R.S.; Tekmal, R.R.; Jolly, C.A.; de Graffenried, L.A. NSAID Use Reduces Breast Cancer Recurrence in Overweight and Obese Women: Role of Prostaglandin-Aromatase Interactions. Cancer Res. 2014, 74, 4446-4457. [CrossRef]

6. Vieno, N.; Sillanpää, M. Fate of diclofenac in municipal wastewater treatment plant-A review. Environ. Int. 2014, 69, 28-39. [CrossRef]

7. Carere, M.; Polesello, S.; Kase, R.; Gawlik, B.M. The Emerging Contaminants in the Context of the EU Water Framework Directive. In Emerging Contaminants in River Ecosystems: Occurrence and Effects under Multiple Stress Conditions; Petrovic, M., Sabater, S., Elosegi, A., Barceló, D., Eds.; Springer International Publishing: Cham, Switzerland, 2016; pp. 197-215. [CrossRef]

8. Stosic, R.; Dunagan, F.; Palmer, H.; Fowler, T.; Adams, I. Responsible self-medication: Perceived risks and benefits of over-the-counter analgesic use. Int. J. Pharm. Pract. 2011, 19, 236-245. [CrossRef] 
9. Madikizela, L.M.; Chimuka, L.J. Occurrence of naproxen, ibuprofen, and diclofenac residues in wastewater and river water of KwaZulu-Natal Province in South Africa. Environ. Monit. Assess. 2017, 189, 348. [CrossRef]

10. Marco-Urrea, E.; Pérez-Trujillo, M.; Cruz-Morató, C.; Caminal, G.; Vicent, T. White-rot fungus-mediated degradation of the analgesic ketoprofen and identification of intermediates by HPLC-DAD-MS and NMR. Chemosphere 2010, 78, 474-481. [CrossRef]

11. Gonda, S.; Kiss-Szikszai, A.; Szúcs, Z.; Balla, B.; Vasas, G. Efficient biotransformation of non-steroid anti-inflammatory drugs by endophytic and epiphytic fungi from dried leaves of a medicinal plant, Plantago lanceolata L. Int. Biodeter. Biodegr. 2016, 108, 115-121. [CrossRef]

12. Bronikowski, A.; Hagedoorn, P.-L.; Koschorreck, K.; Urlacher, V.B. Expression of a new laccase from Moniliophthora roreri at high levels in Pichia pastoris and its potential application in micropollutant degradation. AMB Express 2017, 7, 73. [CrossRef]

13. Marco-Urrea, E.; Pérez-Trujillo, M.; Vicent, T.; Caminal, G. Ability of white-rot fungi to remove selected pharmaceuticals and identification of degradation products of ibuprofen by Trametes versicolor. Chemosphere 2009, 74, 765-772. [CrossRef] [PubMed]

14. Marco-Urrea, E.; Pérez-Trujillo, M.; Blánquez, P.; Vicent, T.; Caminal, G. Biodegradation of the analgesic naproxen by Trametes versicolor and identification of intermediates using HPLC-DAD-MS and NMR. Bioresour. Technol. 2010, 101, 2159-2166. [CrossRef]

15. Borràs, E.; Llorens-Blanch, G.; Rodríguez-Rodríguez, C.E.; Sarrà, M.; Caminal, G. Soil colonization by Trametes versicolor grown on lignocellulosic materials: Substrate selection and naproxen degradation. Int. Biodeter. Biodegr. 2011, 65, 846-852. [CrossRef]

16. Rodarte-Morales, A.I.; Feijoo, G.; Moreira, M.T.; Lema, J. Degradation of selected pharmaceutical and personal care products (PPCPs) by white-rot fungi. World J. Microbiol. Biotechnol. 2011, 27, 1839-1846. [CrossRef]

17. Cruz-Morató, C.; Lucas, D.; Llorca, M.; Rodriguez-Mozaz, S.; Gorga, M.; Petrovic, M.; Barceló, D.; Vicent, T.; Sarrà, M.; Marco-Urrea, E. Hospital wastewater treatment by fungal bioreactor: Removal efficiency for pharmaceuticals and endocrine disruptor compounds. Sci. Total Environ. 2014, 493, 365-376. [CrossRef] [PubMed]

18. Badia-Fabregat, M.; Lucas, D.; Pereira, M.A.; Alves, M.; Pennanen, T.; Fritze, H.; Rodríguez-Mozaz, S.; Barceló, D.; Vicent, T.; Caminal, G. Continuous fungal treatment of non-sterile veterinary hospital effluent: Pharmaceuticals removal and microbial community assessment. Appl. Microbiol. Biotechnol. 2016, 100, 2401-2415. [CrossRef] [PubMed]

19. Olicón-Hernández, D.R.; Camacho-Morales, R.L.; Pozo, C.; González-López, J.; Aranda, E. Evaluation of diclofenac biodegradation by the ascomycete fungus Penicillium oxalicum at flask and bench bioreactor scales. Sci. Total Environ. 2019, 662, 607-614. [CrossRef]

20. Miller, G.L. Use of Dinitrosalicylic Acid Reagent for Determination of Reducing Sugar. Anal. Chem. 1959, 31 , 426-428. [CrossRef]

21. Mtibaà, R.; Olicón-Hernández, D.R.; Pozo, C.; Nasri, M.; Mechichi, T.; González, J.; Aranda, E. Degradation of bisphenol A and acute toxicity reduction by different thermo-tolerant ascomycete strains isolated from arid soils. Ecotoxicol. Environ. Saf. 2018, 156, 87-96. [CrossRef]

22. Zucconi, F.J.B. Evaluating toxicity of immature compost. BioCycle 1981, 22, 54-57.

23. Aranda, E.; Godoy, P.; Reina, R.; Badia-Fabregat, M.; Rosell, M.; Marco-Urrea, E.; García-Romera, I. Isolation of Ascomycota fungi with capability to transform PAHs: Insights into the biodegradation mechanisms of Penicillium oxalicum. Int. Biodeter. Biodegr. 2017, 122, 141-150. [CrossRef]

24. Aus der Beek, T.; Weber, F.A.; Bergmann, A.; Hickmann, S.; Ebert, I.; Hein, A.; Küster, A. Pharmaceuticals in the environment-Global occurrences and perspectives. Environ. Toxicol. Chem. 2016, 35, 823-835. [CrossRef] [PubMed]

25. Gauthier, H.; Yargeau, V.; Cooper, D.G. Biodegradation of pharmaceuticals by Rhodococcus rhodochrous and Aspergillus niger by co-metabolism. Sci. Total Environ. 2010, 408, 1701-1706. [CrossRef] [PubMed]

26. Wen, J.; Gao, D.; Zhang, B.; Liang, H. Co-metabolic degradation of pyrene by indigenous white-rot fungus Pseudotrametes gibbosa from the northeast China. Int. Biodeter. Biodegr. 2011, 65, 600-604. [CrossRef] 
27. González-Abradelo, D.; Pérez-Llano, Y.; Peidro-Guzmán, H.; del Rayo Sánchez-Carbente, M.; Folch-Mallol, J.L.; Aranda, E.; Vaidyanathan, V.K.; Cabana, H.; Gunde-Cimerman, N.; Batista-García, R.A. First demonstration that the ascomycetous halophilic fungi Aspergillus sydowii and Aspergillus destruens are useful in xenobiotic mycoremediation under high salinity conditions. Bioresour. Technol. 2019, 279, $296-297$. [CrossRef]

28. Poraj-Kobielska, M.; Kinne, M.; Ullrich, R.; Scheibner, K.; Kayser, G.; Hammel, K.E.; Hofrichter, M. Preparation of human drug metabolites using fungal peroxygenases. Biochem. Pharm. 2011, 82, 789-796. [CrossRef]

29. Jelic, A.; Cruz-Morató, C.; Marco-Urrea, E.; Sarrà, M.; Perez, S.; Vicent, T.; Petrović, M.; Barcelo, D. Degradation of carbamazepine by Trametes versicolor in an air pulsed fluidized bed bioreactor and identification of intermediates. Water Res. 2012, 46, 955-964. [CrossRef]

30. Cruz-Morató, C.; Ferrando-Climent, L.; Rodriguez-Mozaz, S.; Barceló, D.; Marco-Urrea, E.; Vicent, T.; Sarrà, M. Degradation of pharmaceuticals in non-sterile urban wastewater by Trametes versicolor in a fluidized bed bioreactor. Water Res. 2013, 47, 5200-5210. [CrossRef]

31. Tran, N.H.; Urase, T.; Kusakabe, O. Biodegradation characteristics of pharmaceutical substances by whole fungal culture Trametes versicolor and its laccase. J. Water Environ. Technol. 2010, 8, 125-140. [CrossRef]

(C) 2020 by the authors. Licensee MDPI, Basel, Switzerland. This article is an open access article distributed under the terms and conditions of the Creative Commons Attribution (CC BY) license (http://creativecommons.org/licenses/by/4.0/). 